\title{
GRATITUDE, INDEBTEDNESS, AND REGRET ON RECEIVING A FRIEND'S FAVOR IN JAPAN
}

\author{
Takashi NAITO and Yuriko SAKATA \\ Ochanomizu University, Japan
}

\begin{abstract}
To explore different functions of gratitude and indebtedness, two questionnaire studies were conducted with female university students in Japan. These studies examined the correlations between positive feelings, regret, and indebtedness when receiving a favor, and the resulting feelings such as the enhancement of prosocial motivation (wish to help) and the obligation to help others. The results of Study 1 suggested that positive feelings and indebtedness in a hypothetical helping situation differently correlated with other variables: Positive feelings had a significant positive correlation with the enhancement of prosocial motivation. In contrast, indebtedness had a significant positive correlation with enhancement of obligation (should help). Study 2 was conducted by using positive and socially conceptualized feeling items such as the fulfillment of friendship. Results suggested that the social conceptualization might add obligatory nature to the positive feelings.
\end{abstract}

Key words: gratitude, indebtedness, moral emotion, Japan

Historically, gratitude has been regarded as a moral emotion that can lead to moral behaviors. Also in modern psychology, researchers have conceptualized gratitude as a moral emotion (e.g., Haidt, 2003; McCullough, Kilpatrick, Emmons, \& Larson, 2001). Gratitude is broadly defined as an emotion arising in a person who is helped by others, which can induce moral behaviors, as described by McCullough et al. (2001). In addition, gratitude directed to someone, or something, can be associated with feelings of joy.

\section{Gratitude and related feelings of indebtedness and regret in Japanese people}

People who are helped by others report experiencing a variety of feelings, such as gratitude, indebtedness, and shame. Some social anthropologists have argued that there are cultural differences in feelings that are experienced when receiving a favor. For example, Benedict (1946) reported that Japanese people feel much indebtedness along with gratitude when they receive favors from others. She described that Japanese people sometimes avoid receiving favors, because, "people do not like to shoulder causally the debt of gratitude which on [a Japanese word] implies" (Benedict, 1946, p. 104).

This statement is broadly supported by contemporary cross-cultural studies on support seeking in individualistic and collectivistic cultures (Taylor et al., 2004; Kim, Sherman, Ko, \& Taylor, 2006). For example, Kim et al. (2006) suggested that Asian Americans from collectivistic cultures sought less social support than European

Correspondence concerning this article should be addressed to Takashi Naito, Department of Psychology, Ochanomizu University, 2-1-1, Otsuka, Bunkyoku, Tokyo, Japan (e-mail: naitot@aol.com). 
Americans from more individualistic cultures. They argued that people from collectivistic cultures have a strong orientation towards not destroying their relationships with other people and as a result, that they avoid requesting help from others.

Japanese psychologists, such as Murase (1996) have drawn attention to the dual nature of gratitude and indebtedness in Japanese people. According to Murase, kansha, approximately meaning gratitude in Japanese, contains the connotation of indebtedness, as well as the joyful aspect of thankfulness. Social linguists, such as Ide (1998), Kimura (1994) and Kumatoridani (1999) have also commented on the mixed nature of feeling of gratitude and indebtedness felt by Japanese people. In Japanese society, feelings of thankfulness are verbally expressed using one of two expressions: Arigatou (thank you), which originally implied, "It rarely happens", or sumimasen (I am sorry), which figuratively suggests, "my mind is not calm because I bothered you." Sumimasen is also used when apologizing. The double usage of sumimasen for expressing gratitude and apology has received the attention of socio-linguists. For example, Kimura (1994) explored the usage of sumimasen by gathering 44 instances of using sumimasen during 10 hours of daily conversations by Japanese housewives. He found five functions of sumimasen: requesting, attention-getter, closing marker, regretting, and gratitude. Even though word usage and the underlying mental states are not always identical, the usage of sumimasen suggests the possibility that Japanese people frequently experience mixed feelings of thankfulness and regret or indebtedness in comparison to people from other societies. However, recent studies have suggested that gratitude functions differently from indebtedness (Naito, Wangwan, \& Tani, 2005; Tsang, 2006a; Watkins, Seheer, Ovnicek, \& Kolts, 2006). For example, Watkins, et al. (2006) suggested that gratitude and indebtedness are different concepts by demonstrating that with increasing expectations of return communicated by a gift provided by a benefactor, indebtedness increased but gratitude decreased. The above discussion leads to the question: Are feelings of gratitude, indebtedness and regret have different functions also in Japan, where it has been considered that these feelings are mixed?

It is possible that Japanese people feel positive emotions such as joy and warmth, as well as indebtedness and regret when receiving favors. These feelings are collectively referred to as kansha (gratitude) and they may be functionally different as exemplified by their relation to prosocial motivation (wish to help) and the feelings of obligation to help. The clear distinction between wish and obligation by Japanese people is consistent with their notable distinction between the formal and the personal (Naito and Gielen, 1992). Additionally, it is suggested that there is a social adaptive function of indebtedness and regret in the Japanese settings. For example, Emmons and McCullough (n.d.) have argued on the basis of their research that indebtedness decreases social interactions and "tends to be an aversive psychological state that is distinct from gratitude" (Emmons \& McCullough, n.d., p. 2). The statement leads to a broader question concerning the psychological status of indebtedness or regret in Japanese society: Does the disposition to experience indebtedness or regret decrease social interactions and result in aversive consequences?

In the present study, we set general hypotheses that (a) the concept of gratitude or 
kansha in Japanese society relates to both positive feelings such as joy and indebtedness or regret in receiving others' favors, (b) the positive feelings instead of gratitude, and indebtedness or regret in receiving others' favors lead to different types of motivations to help others: the positive feelings relate to enhancement of prosocial motivation (wish to help), and indebtedness or regret relate to obligation to help, and (c) people who tend to feel strong indebtedness avoid social interactions with others, and then become less satisfied with their lives.

These hypotheses were examined using female Japanese university students, because of their accessibility to the authors. Although using this sample limits the generalizability of the findings, the findings are still of value in suggesting cultural variations in gratitude and other related feelings.

\section{STUDY 1}

To examine the aforementioned hypotheses, we used the following measures: (1) positive feelings including feelings of thankfulness, regret, indebtedness, enhancement of prosocial motivation and a sense of obligation to help others reported in a hypothetical situation of being helped, and (2) social extraversion, and (3) subjective satisfaction with life. In addition, measures of disposition to experience thankfulness (GQ-6) and disposition to feel indebtedness were adopted to confirm the construct validity of the measures in (1).

\section{METHOD}

\section{Participants}

Voluntary respondents of the questionnaire were 135 female university students of a women's university in Tokyo (Mean Age $=19.39, S D=2.69)$.

\section{Instruments}

The questionnaire contained measures of the feelings generated upon receiving others' favors in a hypothetical helping situation and enhancement of prosocial motivation adopted from Naito et al. (2005), Indebtedness Scale (measure of disposition to experience indebtedness) newly constructed based on the item analysis by Greenberg and Westcott (1983), GQ-6 (measure of disposition to experience gratitude in life, constructed by McCullough, Emmons, and Tsang, 2002), Satisfaction With Life Scale (SWLS) (Diener, Emmons, Larsen, \& Griffin, 1985), and Interpersonal Orientation Scale (IOS-V) (Saito \& Nakamura, 1987) (Table 1).

Questions on feelings evoked by being helped (15 items). We revised and used a part of the questionnaire constructed by Naito et al. (2005). The original questionnaire measures "positive feelings," "indebtedness," and "negative feelings" in receiving others' favors. The participants were presented with the following hypothetical story and question items.

"Suppose you are a university student who lives alone. One day, you are injured and are unable to walk. Your friend, a female university student, willingly brings your meals from her home once a day, spending 20 minutes walking from her house to your room."

Then, the participants were asked to rate the strength of their feelings in the situation on a five-point scale, from 1 (not at all) to 5 (very much). Because the consistency of indebtedness items in the preliminary 
Table 1. Means and SDs of the Variables Used in the Study 1

\begin{tabular}{lcl}
\hline Variables (possible values) & Mean & SD \\
\hline Positive Feelings (4-20) & 16.16 & 2.85 \\
Regret for bothering (4-20) & 16.01 & 2.95 \\
Indebtedness(3-15) & 9.15 & 2.90 \\
Negative Feelings(4-20) & 5.92 & 2.74 \\
Prosocial Motivation(4-20) & 15.28 & 2.61 \\
Obligation (4-20) & 13.73 & 3.04 \\
Indebtedness Scale (6-42) & 26.13 & 5.30 \\
GQ6 (6-42) & 30.24 & 5.41 \\
SWLS (5-35) & 18.64 & 5.56 \\
IOS-V (17-85) & 56.17 & 7.61 \\
\hline
\end{tabular}

1. $N=135$

study using 196 female university students was relatively low $(\alpha=.73)$ compared with the other two categories $(\alpha=.82$, and .83), the author reexamined these items and divided the category, "indebtedness", into two conceptually different categories on the basis of the result of the factor analysis, i.e., "regret for bothering" and "indebtedness". The former category contained items that described feelings of regret for the benefactor's costs in helping and feeling sorry for the benefactors in those situations. The latter category involved feelings of obligation to return the favor. Finally, the following 16 feelings were selected as question items on feelings evoked by being helped: "joy," "pleasant," "warmth," "happiness," as positive feeling items (4 items), "feeling sorry," "uneasiness towards the helper," "regret for causing a problem," "regret for bothering the friend," as regret for bothering items (4 items), "indebtedness," feeling of owing to the helper," and "feeling beholden," as indebtedness items (3 items), and "feeling troubled," "unpleasantness," "depression," and "annoyance" as negative feelings (4 items). In addition, "gratitude kansha" was included to the item list. The participants were asked to indicate the strength of their feeling on a five-point scale, from 1 (not at all) to 5 (very much).

Questions on enhancement of prosocial motivation. The following four items were used to measure enhancement of prosocial motivation after accepting help in the hypothetical situation.

"After receiving this friend's help in the hypothetical scenario, please answer the following questions" (1) "More than before, would you want to help the friend, if she were distressed in a similar situation?" (Benefactor-similar situation), (2) "More than before, would you want to help the friend, if she needed help in other situations?" (Benefactor-other situation), (3) "More than before, would you want to help other people, if they were distressed in similar situations?" (Stranger-similar situation), (4) "More than before, would you want to help others in distress?" (Stranger-other situation).

The participants were asked to respond to the questions on a 5-point scale from $1=$ "No, would not want to help more" to $5=$ "Yes, would want to help very much". The variable of enhancement of prosocial motivation was constructed by summing up the ratings to the four questions.

Questions on enhancement of obligation. In addition to the questions on enhancement of prosocial motivation, questions on enhancement of obligation were added. These items were nearly identical to the questions on enhanced prosocial motivation except that they focused on feelings of obligation to help the other person, e.g., "More than before, do you feel obligated to help the friend, if she were similarly distressed?"

Gratitude Questionnaire-Six-Item Form GQ-6 (6 items). McCullough, Emmons, and Tsang (2002) developed a six-item form of the Gratitude Questionnaire GQ-6 to measure individual differences in the tendency to experience thankfulness in daily life, items such as the following: "I have so much in life to be 
thankful for"; "If I had to list everything that I felt grateful for, it would be a very long list". The respondents were asked to respond to the questions on a 7-point scale, varying between 1 (strongly disagree) to 7 (strongly agree). They reported that GQ-6 correlated significantly with the Satisfaction With Life Scale (Diener et al., 1985), Subjective Vitality Scale (Ryan \& Frederick, 1997), Subjective Happiness Scale (Lyubomirsky \& Lepper, 1999), Optimism in Life Orientation Test (Scheier, Carver, \& Bridges, 1994), Hope Scale (Snyder, et al., 1991), the disposition toward empathy (Davis, \& Oathout, 1987), Positive and Negative Affect Scales, and Agreeableness, Neuroticism, and Openness in The Big Five Inventory (John \& Srivastava, 1999).

Indebtedness Scale (6 items). Greenberg and Westcott (1983) constructed an indebtedness scale and showed the results of item analysis. Because they reported some inhomogeneous items, we selected six items from their items by the criterion that the item tapped solely the feelings of obligation to reciprocate. For example, the items that describe the orientation to give back more than was given, and an orientation to feel thankfulness with pleasure were not included in the scale used in the present study. Finally, we adopted six items from the original eleven items. The items adopted in the present study were as follows: "If someone saves your life, you are forever in their debt." "One should return favors from a friend as quickly as possible in order to preserve the friendship." "Owing someone a favor makes me uncomfortable." "As a rule, I don't accept a favor if I can't return the favor." "If someone [who is equal to you] (added by the authors to adapt to Japanese society where the relation to "someone" is critical to the judgment) pays for my dinner or invites me to eat at their place, I feel obligated to buy them dinner the next time or to invite them to eat at my place." "I get very upset when I discover I have forgotten to return something I borrowed". The respondents were asked to respond to the questions on a 7-point scale, varying between 1 (strongly disagree) to 7 (strongly agree).

Satisfaction with Life Scale (SWLS), and Interpersonal Orientation Sale (IOS-V). SWLS consists of 5 items, and has a 2-month test-retest correlation coefficient of .82 (Diener et al., 1985). The respondents were asked to respond to the questions on a 7-point scale, varying between 1 (strongly disagree) to 7 (strongly agree). IOS-V is a Japanese adaptation of the Interpersonal Orientation Scale, which is based on the theory of interpersonal orientation (IO) described by Swap and Rubin (1983). A high IO indicates sensitivity in personal relationships, interest in exchanges with others and confidence in the ability to interact appropriately (Saito \& Nakamura, 1987). IO scale has well-established reliability and validity and consists of 17 items to be rated on a 5-point scale. The sample items are as follows: "I am a sociable person" and "It is useless to consider others' feelings" (reversed). We used the total IO score to measure social extroversion or positive orientation to social interaction,

Finally, the participants were presented the question items in the following order: The questions on feelings in the hypothetical situation, enhancement of prosocial motivation, enhancement of obligation, GQ6, SWLS, and IOS-V. The items of GQ-6, and SWLS were translated into Japanese by the authors, and then, back translated by a British graduate student who was specializing in Japanese literature to check the accuracy of the translation.

\section{RESUlTS AND DISCUSSION}

\section{Factor Structure of Feeling Items}

In order to examine the hypothesized categories or clusters of the 16 feeling items, a factor analysis was conducted on the items. Results of a principal component analysis suggested four factors with eigen values over 1.0 for further analysis. Then, a principal axis factor analysis with promax-oblique rotation was conducted for the first four factors. These four factors explained $62.4 \%$ of the total variance. The factor-loading matrix supported the hypothesized categories or clusters of the items (Table 2). Namely, the five positive feeling items had high loadings on the first factor, the four negative feeling items had high loadings on the second factor, the four regret for bothering items had high loadings on the third factor, and the four items of indebtedness had high loadings on the fourth factor. Correlations of Factor 1 with Factor 2, 3, and 4 were -.63, -.06, and -.04, 
Table 2. Factor Pattern of Feelings Evoked by Being Helped

\begin{tabular}{|c|c|c|c|c|}
\hline Factor & 1 & 2 & 3 & 4 \\
\hline Warmth & .87 & .07 & .06 & .01 \\
\hline Joy & .78 & -.09 & -.01 & .01 \\
\hline Happiness & .76 & .03 & -.03 & .00 \\
\hline Pleasant & .64 & .00 & -.23 & .10 \\
\hline Unpleasantness & .05 & .93 & -.05 & -.05 \\
\hline Depression & .04 & .90 & .12 & -.04 \\
\hline Annoyed & -.05 & .88 & -.05 & -.04 \\
\hline Feeling troubled & -.11 & .66 & .04 & .14 \\
\hline Regret causing a problem & -.06 & -.01 & .87 & .01 \\
\hline Uneasiness & -.06 & .06 & .72 & .01 \\
\hline Feeling sorry & .08 & -.02 & .70 & .00 \\
\hline Regret for bothering & .02 & .02 & .67 & .09 \\
\hline Owing a lot to the helper & -.01 & -.04 & .04 & .89 \\
\hline Feeling beholden & -.05 & .22 & -.05 & .72 \\
\hline Indebtedness & .10 & -.16 & .15 & .62 \\
\hline Gratitude & .47 & -.06 & .29 & -.11 \\
\hline Eigen value & 3.88 & 4.41 & 3.07 & 2.89 \\
\hline$\%$ variance explained & 24.23 & 27.58 & 19.21 & 18.06 \\
\hline
\end{tabular}

1. $N=135$.

2. Correlations of factor 1 with factor 2,3 , and 4 were -.63,-.06, and -.04, correlations of factor 2 with factor 3 and 4 were .18 and .36 , and correlation between factor 3 and 4 was .50 .

3. Values in boldface are factor loadings above .60 .

while correlations of Factor 2 with Factor 3 and 4 were .18 and .36, and a correlation between Factor 3 and 4 was .50 .

\section{Reliability and Validity of Variables}

Cronbach's alpha coefficients for positive feelings, regret for bothering, indebtedness, negative feelings, enhanced prosocial motivation, and enhanced obligation were $.82, .84, .80, .91, .79$, and .80, respectively. Cronbach's alpha coefficients for GQ-6, the Indebtedness Scale, SWLS, and IOS-V were, .77, .69, .82, and .80. To check the construct validity of positive feelings, regret for bothering, indebtedness, and negative feelings, correlations with GQ-6 and the Indebtedness Scale were calculated. As shown in Table 3, GQ-6 had a significant correlation with positive feelings, and the Indebtedness Scale had significant correlations with indebtedness and regret for bothering. These results confirm the validity of the feeling variables using the hypothetical story. 
Table 3. Correlations between Four Categories of Feelings Evoked by Being Helped, GQ-6, Indebtedness Scale, Enhancement of Prosocial Motivation, Obligation, SWLS, and IOS-V

\begin{tabular}{|c|c|c|c|c|c|c|c|c|c|}
\hline & 1 & 2 & 3 & 4 & 5 & 6 & 7 & 8 & 9 \\
\hline \multicolumn{10}{|l|}{ 1. Positive feelings } \\
\hline 2. Negative feelings & $-.55^{* * *}$ & & & & & & & & \\
\hline 3. Regret for bothering & -.12 & .21 & & & & & & & \\
\hline 4. Indebtedness & -.03 & $.33 * *$ & $.48^{* * *}$ & & & & & & \\
\hline 5. GQ-6 & $.32 * *$ & -.14 & -.06 & -.19 & & & & & \\
\hline 6. Indebtedness Scale & -.08 & $.32 * *$ & $.36^{* * *}$ & $.55^{* * *}$ & -.15 & & & & \\
\hline 7. Enhancement of prosocial motivation & $.48^{* * *}$ & $-.37 * * *$ & .06 & -.02 & $.30^{*}$ & -.04 & & & \\
\hline 8. Enhancement of obligation & .22 & -.14 & .22 & $.37 * * *$ & -.01 & $.39^{* * *}$ & $.54 * *$ & & \\
\hline 9. SWLS & $.29 *$ & -.22 & -.21 & -.23 & $.31^{*}$ & -.10 & .15 & -.06 & \\
\hline 10. IOS-V & $.38^{* * *}$ & $-.35^{* *}$ & -.08 & -.09 & $.41^{* * *}$ & -.11 & $.38 * * *$ & .23 & .20 \\
\hline
\end{tabular}

1. $N=135 . * p<.05 . * * p<.01 . * * * p<.001$.

2. $\alpha$ values are adjusted by dividing $\alpha$ of single test by the number of tested correlations 45 .

\section{Relation of Enhancement of Prosocial Motivation and Obligation with Feelings Evoked by} Being Helped

Concerning the status of item on gratitude, or "kansha" in a hypothetical helping situation was examined by a stepwise multiple regression analysis of "gratitude" item, using the other 15 feeling items as independent variables. Results indicated that "regret for bothering the friend" and "Joy" were entered as significant independent variables ( $b=.22, .63$, respectively, $p<.001$ for both of them, $R^{2}=.43$ ). These results supported the aforementioned hypothesis that the concept of gratitude in Japanese relates to positive feelings and indebtedness or regret for bothering. Additionally, this status of gratitude among feeling items was reflected on the factor loadings of the item of gratitude on the positive feeling factor (.47) and regret for bothering factor (.29).

Concerning predictions (b) and (c), we conducted a multiple regression analyses with enhancement of prosocial motivation and enhancement of obligation using positive feelings, negative feelings, regret for bothering, and indebtedness as independent variables. As shown in Table 4, positive feelings had significant positive partial regression coefficients for enhancement of prosocial motivation. This result, along with the simple correlations supports the previous findings that showed a positive relation between gratitude and prosocial behaviors (Emmons \& McCullough, 2003; Tsang, 2006b). In contrast, indebtedness had significant positive partial regression coefficients and negative feelings had a significant negative partial regression coefficient for enhancement of obligation. These results are indicative of the different functions of positive feelings and indebtedness, even though enhancement of prosocial motivation and obligation were correlated together $(r=.54, p<.001)$.

These findings also provide an explanation of the inconsistent results on the relation 
Table 4. Standardized Partial Regression Coefficients of Positive Feelings, Regret for Bothering, and Indebtedness in Multivariate Regression Analyses with Enhancement of Pro-social Motivation, and Obligation

\begin{tabular}{lccccc}
\hline & $\begin{array}{l}\text { Positive } \\
\text { feelings }\end{array}$ & $\begin{array}{l}\text { Negative } \\
\text { feelings }\end{array}$ & $\begin{array}{l}\text { Regret for } \\
\text { bothering }\end{array}$ & Indebtedness & $R^{2}$ \\
\hline Enhancement of Prosocial Motivation & $\begin{array}{c}.40^{* * *} \\
\left(.48^{* * *}\right)\end{array}$ & $\begin{array}{c}-.17 \\
(-.37 * * *)\end{array}$ & $\begin{array}{c}.16 \\
(.06)\end{array}$ & $\begin{array}{c}-.03 \\
(-.02)\end{array}$ & .26 \\
Enhancement of Obligation & .11 & $-.23 *$ & .08 & $.42^{* * *}$ & .23 \\
\hline
\end{tabular}

1. $N=135 . * p<.05 . * * p<.01 . * * * p<.001$.

2. Numbers in parenthesses are simple correlations. $\alpha$ values are adjusted by dividing $\alpha$ of single test by the number of tested correlations, 8 .

between gratitude and closeness in benefactors and receivers. DeCooke (1992) showed that 6,8 and 11 year-olds reported stronger sense of obligation to reciprocate to acquaintances than friends. However, Naito et al. (2005) showed that both Japanese and Thai undergraduate students reported the strongest indebtedness to strangers among parents, friends and strangers, but they also reported the least positive feelings toward strangers. Besides the cultural and age differences, the inconsistency of these findings can be explained by the difference of question items adopted by these studies: the questions that tap on the wish to repay or the obligation to repay may have made a difference to the results.

Relation of Social Extraversion and SWLS with GQ-6, the Indebtedness Scale, and Feelings Evoked by Being Helped

To examine the prediction about the relation of social extraversion and SWLS, simple correlations of relation of IOS-V and SWLS with GQ-6, the Indebtedness Scale, and the variable of feelings evoked by being helped were calculated. As shown in Table 3, the Indebtedness Scale, feeling of indebtedness, and regret for bothering did not significantly correlate with extraversion IOS-V, whereas GQ-6, positive feelings, and negative feelings did significantly correlate with IOS-V. The results suggest that indebtedness may not be a negative factor in reducing the social orientation. In addition, as for the prediction about SWLS, although GQ-6 and positive feelings had significant positive correlation with SWLS, negative feelings, regret for bothering, indebtedness, and the Indebtedness Scale did not. The results of IOS-V and SWLS question the inference that the Japanese students who tend to feel strong indebtedness avoid social interactions with others, and were less satisfied with their lives. Therefore, variables other than social extraversion are needed to explore the relation between indebtedness and social interactions. It is plausible that in the process of interacting with others, people that tend to feel strong indebtedness may feel anxiety.

The relationships between the variables used in the study were also examined through a path analysis with maximum-likelihood estimation in AMOS Version 4.0 
Table 5. Factor Structures of Feelings Evoked by Being Helped by a Close Friend

\begin{tabular}{|c|c|c|c|c|c|}
\hline Items & F1 & F2 & F3 & $\mathrm{F} 4$ & F5 \\
\hline Deepening of the bond with friend & .96 & -.08 & .08 & -.10 & .00 \\
\hline Happiness by confirmation of friendship & .90 & -.09 & .24 & -.02 & -.01 \\
\hline Intimacy with friend & .87 & -.02 & -.08 & -.05 & .08 \\
\hline Warmth of the friend's feeling & .63 & .19 & -.20 & .08 & -.05 \\
\hline Regret causing a problem & -.02 & .94 & .08 & -.02 & -.04 \\
\hline Regret for bothering the friend & -.05 & .88 & -.01 & .06 & -.01 \\
\hline Uneasiness & .04 & .87 & .05 & -.13 & .10 \\
\hline Feel miserable & .04 & .00 & .91 & .06 & .00 \\
\hline Lost confidence & .04 & .03 & .86 & -.01 & -.09 \\
\hline Feel ashamed & .01 & .10 & .80 & .07 & .07 \\
\hline Glad to have had no trouble & -.20 & .01 & .05 & .87 & -.02 \\
\hline It was really a big help & .17 & .03 & .04 & .77 & -.08 \\
\hline Everything went well & .00 & -.15 & .05 & .63 & .19 \\
\hline Owing a lot to the helper & .01 & .00 & -.03 & .12 & .84 \\
\hline Indebtedness & .14 & .04 & -.12 & .04 & .82 \\
\hline Feeling beholden & -.19 & .00 & .19 & -.15 & .61 \\
\hline Gratitude towards a friend & .32 & .16 & -.17 & .22 & .01 \\
\hline$\%$ variance explained & 23.41 & 19.93 & 9.88 & 8.77 & 7.19 \\
\hline Correlation between factors & $\mathrm{F} 1$ & $\mathrm{~F} 2$ & F3 & $\mathrm{F} 4$ & \\
\hline $\mathrm{F} 2$ & .29 & & & & \\
\hline F3 & -.24 & .14 & & & \\
\hline $\mathrm{F} 4$ & .21 & .26 & .02 & & \\
\hline F5 & -.04 & .28 & .26 & .21 & \\
\hline
\end{tabular}

1. Values in boldface are factor loadings above .50 .

(Arbuckle \& Wothke, 1999). The analysis supported the previous analysis. Predicted paths and correlations are shown in Fig. 1. The goodness-of-fit indices indicate a relatively good fit between the model and the data (i.e., $\mathrm{GFI}=.976$; $\mathrm{CFI}=.995$; RMSEA $\left.=.030, \chi^{2}(12)=13.42, p=.34\right)$. Figure 1 shows that both GQ-6 and positive feeling had significant positive paths to enhancement of prosocial motivation $(b=.19$, and $.27, p<.01$ for both). In contrast, the Indebtedness scale and feelings of indebtedness had significant paths to enhancement of obligation $(b=.31$ and $.28, p<.01)$, but caring for others did not have a significant path to enhancement of obligation $(b=-.01, n s)$. Additionally, negative feelings had positive relation to Feelings of Indebtedness and the 


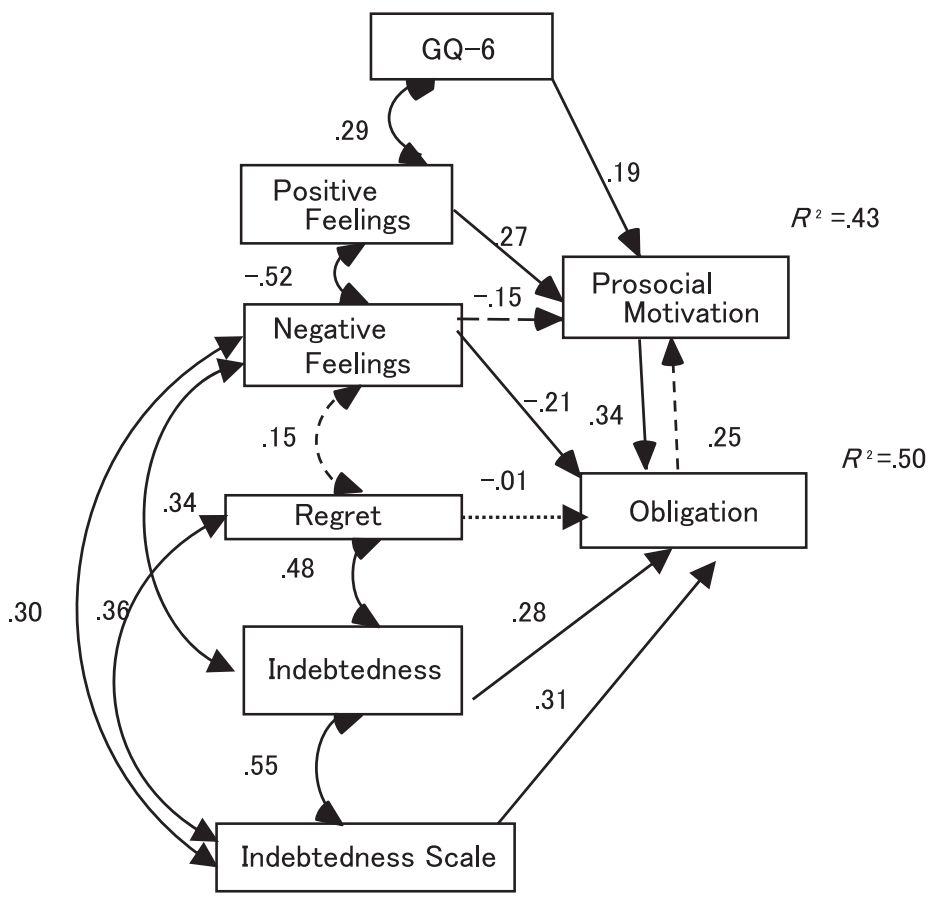

Fig. 1. Path diagram $(N=135)$

For broken paths and solid paths, the coefficients are statistically significant at .05 level and .01 level respectively. For dotted path, the coefficient is not statistically significant. GFI $=.976$, $\mathrm{CFI}=.995$; root mean square error of approximation $(\mathrm{RMSEA})=.030, \chi^{2}(12)=13.42, p=.34$

Indebtedness score $(p r=.30$ and $.34, p<.01)$, but had a negatively significant path to enhancement of obligation $(b=-.21, p<.01)$.

\section{STUDY 2}

Study 2 was conducted to reexamine the finding that positive feelings with gratitude related to prosocial motivation to help others, and indebtedness related to obligation. The items of positive feelings adopted in Study 1 were primary feelings such as joy and warmth. However, it is plausible that people experience more conceptualized feelings, such as fulfillment of friendship with benefactors when receiving favors. In such cases, the receivers may come to feel an obligation to help others, as a result of receiving favors from others. Certain socially conceptualized feelings that are defined here as feelings interpreted in terms of social concepts may result in an obligation in receivers, leading them to help others. Therefore, it is possible that the findings in Study 1 were limited to the primary feelings of positive feelings.

To examine this possibility, we conducted Study 2, where the list of feelings in Study 1 was changed to include socially constructed feelings. 


\title{
METHOD
}

\author{
Participants \\ Voluntary respondents to the questionnaire were 164 students of a women's university in Tokyo, Japan \\ (Mean Age $=19.18$ and $S D=2.02$ ) that participated in Study 1 .
}

\section{Questionnaire}

The questionnaire was identical to those in Study 1, with the following exceptions. First, the words and phrases used in questions on feelings evoked by receiving help were specified by referring to the comprehensive list developed by Greenberg and Westcott (1983). The adopted categories were as follows: fulfillment of friendship; goal achievement; indebtedness; regret for bothering benefactors; and threat to selfesteem. The adopted words and phrases are shown in Table 5.

Second, the relevance of the hypothetical story used in Study 1 was reexamined by interviews to elicit the plausibility of the story. As a result, the content of the helping event was changed to "delivered notes and other class material and explained their content for about an hour." Third, questions on subjective judgments about the helping (4 items) were added as controlling variables. These questions were constructed as influential variables, as suggested by Tesser, Gatewood, and Driver (1968). The respondents were asked to respond to the following questions on a five-point, or a seven-point scale: desirability of the favor, obligation to help, gains of the recipient, and cost to the benefactors. In this paper, analyses using these variables are not reported, because our conclusions did not change as a result of the controlling for these variables. The questionnaires were delivered in an introductory class to moral education classes with questionnaires of identity status that was used for another research.

\section{RESULTS AND DISCUSSION}

\section{Construction of Variables}

To confirm the five categories of feelings felt in being helped, a factor analysis with promax rotation was conducted for the 17 feeling items presented after the story (Table 5). Factor 1 had a high factor loading for the five items of fulfillment in friendship, and the other factors had a high factor loading as follows: factor 2 in three items of regret for bothering; factor 3 in three items of threat to self-esteem; factor 4 in three items of goal achievement; factor 5 in three items of indebtedness.

The scores of items included in each category were totaled so as to construct five variables. Each of the four items of enhancement of prosocial motivation and enhancement of obligation was also totaled, and two variables were constructed (Table 6).

\section{Reliability and Validity of Variables}

To check the construct validity of fulfillment in friendship, goal achievement, regret for bothering, indebtedness, and threat to self-esteem, correlations of these variables with GQ-6 and the Indebtedness Scale were calculated. The results confirmed the validity of the feelings variables: GQ-6 had a significant correlation with fulfillment of friendship, and the Indebtedness Scale had a significant correlations with regret for bothering, indebtedness, and threat to self-esteem (Table 7). 
Table 6. Means and Standard Deviations of the Variables used in Study 2

\begin{tabular}{llll}
\hline \multicolumn{1}{c}{ Variables } & $\alpha$ & Mean & $S D$ \\
\hline Fulfillment in friendship & .82 & 22.68 & 2.81 \\
Goal achievement & .63 & 10.85 & 2.03 \\
Regret for bothering & .89 & 13.54 & 2.13 \\
Indebtedness & .67 & 9.20 & 2.72 \\
Thereat to self-esteem & .83 & 4.45 & 1.95 \\
Enhancement of prosocial motivation & .79 & 15.71 & 2.53 \\
Enhancement of obligation & .85 & 13.54 & 3.12 \\
GQ6 & .73 & 31.10 & 4.87 \\
Indebtedness Scale & .64 & 25.34 & 5.04 \\
\hline
\end{tabular}

Table 7. Correlations of Five Categories of Feelings Evoked by Being Helped with GQ-6 and the Indebtedness Scale

\begin{tabular}{lccccc}
\hline & $\begin{array}{c}\text { Fulfillment of } \\
\text { friendship }\end{array}$ & $\begin{array}{c}\text { Goal } \\
\text { achievement }\end{array}$ & $\begin{array}{c}\text { Regret for } \\
\text { bothering }\end{array}$ & Indebtedness & $\begin{array}{c}\text { Thereat to } \\
\text { self esteem }\end{array}$ \\
\hline GQ-6 & $.28^{* *}$ & -.05 & .21 & -.03 & .09 \\
Indebtedness Scale & -.01 & .16 & $.29^{* *}$ & $.33^{* * *}$ & $.33^{* * *}$ \\
\hline
\end{tabular}

1. $N=164 . * p<.05 . * * p<.01 . * * * p<.001$.

2. $\alpha$ values are adjusted by dividing $\alpha$ of single test by the number of tested correlations, 10 .

\section{Relation of Enhancement of Prosocial Motivation and Obligation with Feelings Evoked by Being Helped}

We conducted a multivariate regression analysis with enhancement of prosocial motivation and enhancement of obligation using fulfillment in friendship, goal achievement, regret for bothering, indebtedness, and threat to self-esteem as independent variables. As shown in Table 8, fulfillment in friendship had a significant positive partial regression coefficient for enhancement of prosocial motivation and enhancement of obligation. This result supports the idea that some of the socially conceptualized positive feelings in receiving favors relate to the obligation to help others.

In contrast, only threat to self-esteem other than fulfillment of friendship had a significant negative partial regression coefficient for enhancement of obligation. Against the findings in Study 1, both indebtedness and regret for bothering failed to have significant regressions $(.05<p<.10)$, although the values were in the predicted directions. However, the significant simple correlation between regret for bothering and enhancement of obligation $(r=.29, p<.01)$ suggested that the non-significant partial coefficient was due to the correlation between independent variables, especially between indebtedness and regret for bothering $(r=.24)$. 
Table 8. Standardized Partial Regression Coefficients of Fulfillment in Friendship, Goal Achievement, Regret for Bothering, Indebtedness, and Threat to Self Esteem in Multivariate Regression Analyses with Enhancement of Pro-social Motivation, and Obligation

\begin{tabular}{lcccccc}
\hline & $\begin{array}{c}\text { Fulfillment of } \\
\text { friendship }\end{array}$ & $\begin{array}{c}\text { Goal } \\
\text { achievement }\end{array}$ & $\begin{array}{c}\text { Regret for } \\
\text { bothering }\end{array}$ & Indebtedness & $\begin{array}{c}\text { Thereat to } \\
\text { self esteem }\end{array}$ & $R^{2}$ \\
\hline $\begin{array}{c}\text { Enhancement of } \\
\text { prosocial motivation }\end{array}$ & $\begin{array}{c}.43^{* * *} \\
\left(.43^{* * *}\right)\end{array}$ & $\begin{array}{c}-.02 \\
(.08)\end{array}$ & $\begin{array}{c}.05 \\
(.19)\end{array}$ & $\begin{array}{c}.08 \\
(-.04)\end{array}$ & $\begin{array}{c}.04 \\
.00)\end{array}$ & .19 \\
$\begin{array}{c}\text { Enhancement of } \\
\text { obligation }\end{array}$ & $.23^{* *}$ & -.01 & $.14^{+}$ & $.14^{+}$ & $.19^{*}$ & .17 \\
\hline
\end{tabular}

1. ${ }^{+} p=.10{ }^{*} p=.05 . * * p=.01 . * * * p=.001$.

2. $N=164$

3. Numbers in parenthesses are simple correlations. $\alpha$ values are adjusted by dividing $\alpha$ of single test by the number of tested correlations, 10 .

\section{GeNERAL DisCuSSION AND CONCLUSIONS}

The results suggest that even in the society where gratitude and indebtedness are intermingled, the underlying feelings of the positive feelings and indebtedness resulting from receiving a favor have different functions. The main results were as follows. (1) the item of gratitude or kansha correlated with both positive feelings and remorse for bothering in the configuration of feelings when receiving a favor (Study 1), (2) positive feelings such as warmth in receiving favors related to enhancement of prosocial motivation, and in contrast, indebtedness (Study 1) or regret for bothering (Study 2) related to enhancement of obligation to help others. (3) People who tend to feel stronger feelings of indebtedness did not avoid social interactions with others, but had fewer score on SWLS (Study 1). (4) Socially conceptualized positive feelings, such as the feeling of fulfillment caused by friendships had a positive relationship to the enhancement of obligations, as well as to prosocial motivation. These results suggest that feelings related to gratitude interacted with variables related to social exchange, such as moral concepts.

Some of the limitations of the current studies are noted below. First, the two studies examined the correlation between gratitude and other variables in the context of given scenarios. Some studies have suggested that situational variables influence feelings of gratitude (e.g., Tesser et al., 1968). Among them, it is plausible that the correlations between the variables used in the present study may vary, when the relationships between the people being helped and the benefactors change. Further studies using a variety of different relationships may bring useful information on situational factors related to feelings of gratitude.

Second, the participants of the present studies were limited to female university students. Therefore, our findings may not generalize to male students and to other age groups. Recent studies have shown that female university students feel more gratitude than males in situations of being helped (Naito et al., 2005; Kashdan, Mishra, Breen \& Froh, 2009). These results may be explained by the gender difference in social 
orientation: Male students may have difficulty in acknowledging the fact that others are helping them, because males have a stronger orientation to independency than females. There is insufficient evidence to discuss gender difference in correlations between gratitude, indebtedness, prosocial motivation and feelings of obligation, as opposed to the magnitude of these feelings. However, it is possible to argue that in male students correlation between gratitude and feelings of obligation to help others may be larger than female students, so that male students are more defensive to feel thanks to others than females.

Third, the method used in these studies, in which the participants were asked to respond to questions about a scenario may tap the cognitive aspects of gratitude and the related feelings more heavily than the emotional response. In other words, participants had to infer their feelings on the basis of the information given in the scenario, such as the intention of the benefactor, among others. Therefore, the scope of the present studies was limited to the cognitive aspects of gratitude and related feelings.

In addition, the studies had certain conceptual limitations. Namely, regret, indebtedness and thankfulness are not static psychological states. The dynamic interactions between joyful aspects of gratitude and indebtedness have been suggested in the field of psychotherapy in Japan (Murase, 1986; Reynolds, 1983). Naikan therapists have suggested that indebtedness is transferable to thankfulness at the final stages of therapy. In Naikan therapy, clients recollect and examine memories of receiving care and benevolence from a particular person at a particular time in the past, for example, from their mother when they were 6 years old and 7 years old. They are also asked to recall memories of repaying love and care to that person. Through this process, clients experience both gratitude and indebtedness towards others, and as a result, they are expected to be aware of the basic interdependency inherent in human existence (Murase, 1986). Thus, in the process of the therapy, the clients feel deep indebtedness to their mothers, and significant others. This feeling of indebtedness could lead to depression. The clients are expected to transform their depression to positive feelings of gratitude. Murase (1986) suggests, "the more universal basis of Naikan may be found in its emphasis on insight into, and a positive relationship with, one's guilt, in contrast to the mere feeling of guilt" (Murase, 1986, p. 396). Considering the broader concept of gratitude would result in focusing on the interactive nature and integrative aspects of gratitude. These aspects of gratitude remain to be investigated in the future.

\section{REFERENCES}

Arbuckle, J. L., \& Wothke, W. 1999. AMOS 4.0 User's Guide. Chicago: Small-Waters Corporation. Benedict, R. 1946. Chrysanthemum and the sword: Patterns of Japanese culture. Boston: Houghton Mifflin. Davis, M. H., \& Oathout, H. A. 1987. Maintenance of satisfaction in romantic relationships: Empathy and relational competence. Journal of Personality and Social Psychology, 53, 397-410.

DeCooke, P. A. 1992. Children's understanding as a feature of reciprocal help exchange between peer. Developmental Psychology, 28, 948-954.

Diener, E., Emmons, R. A., Larsen, R. J., \& Griffin, S. 1985. The Satisfaction With Life Scale. Journal of Personality Assessment, 49, 71-75. 
Emmons, R. A., \& McCullough, M. E. 2003. Counting blessings versus burdens: An experimental investigation of gratitude and subjective well-being in daily life. Journal of Personality and Social Psychology, 84, 377-389.

Emmons, R. A., \& McCullough, M. E. (n.d.) Highlights from the research project on gratitude and thanksgiving. downloaded October 24, 2006, http://psychology.ucdavis.edu/labs/emmons/.

Greenberg, M. S., \& Westcott, D. R 1983. Indebtedness as a mediator of reactions to aid. In J. D. Fisher, A. Nadler \& B. M. DePaulo (Eds.), New directions in helping, Vo1.1: Recipient reaction to aid (pp. 85112). New York: Academic Press.

Haidt, J, 2003. The moral emotions. In R. J. Davidson, K. R. Scherer \& H. H. Goldsmith (Eds.), Handbook of affective sciences (pp. 852-870). London: Oxford University Press.

Ide, R. 1998. 'Sorry for your kindness': Japanese interactional ritual in public discourse. Journal of Pragmatics, 29, 509-529.

John, O. P., \& Srivastava, S. 1999. The Big Five trait taxonomy: History, measurement, and theoretical perspectives. In L. A. Pervin, \& O. P. John (Eds.), Handbook of personality: Theory and research, 2nd ed (pp. 102-138). New York: Guilford.

Kashdan, T. B., Mishra, A., Breen, W. E., \& Froh, J. 2009. Gender differences in gratitude: examining appraisals, narratives, the willingness to express emotions, and changes in psychological needs. Journal of Personality, 77, 691-730.

Kim, H. S., Sherman, D. K., Ko, D., \& Taylor, S. E. 2006. Pursuit of comfort and pursuit of harmony: Culture, relationships, and social support seeking. Personality and Social Psychology Bulletin, 32, 1595-1607.

Kimura, K. 1994. The multiple functions of sumimasen. Issues in Applied Linguistics, 52, 279-302.

Kumatoridani, T. 1999. Alternation and co-occurrence in Japanese thanks. Journal of Pragmatics, 31, 623642.

Lyubomirsky, S., \& Lepper, H. S. 1999. A measure of subjective happiness: Preliminary reliability and construct validation. Social Indicators Research, 46, 137-155.

McCullough, M. E., Emmons, R. A., \& Tsang, J.-A. 2002. The graceful disposition: a conceptual and empirical topography. Journal of Personality and Social Psychology, 82, 112-127.

McCullough, M. E., Kilpatrick, S. D., Emmons, R. A., \& Larson, D. B. 2001. Is gratitude a moral affect? Psychological Bulletin, 127, 249-266.

Murase, T. 1986. Naikan therapy. In T. S. Lebra \& W. P. Lebra (Eds.), Japanese culture and behavior: Selected readings Rev. ed. (pp. 388-397). Honolulu: University of Hawaii Press.

Murase, T. 1996. Jiko no rinshosinrigaku: Naikan [Clinical psychology on self: Naikan therapy]. Tokyo: Seisinshobou.

Naito, T., \& Gielen, U. 1992. Tatemae and honne: A study of moral relativism in Japanese culture. In U. P. Gielen, L. L. Adler \& N. Milgram (Eds.), Psychology in international perspective (pp. 161-172). Amsterdam: Swets and Zeitlinger.

Naito, T., Wangwan, J., \& Tani, M. 2005. Gratitude in university students in Japan and Thailand. Journal of Cross-cultural Psychology, 36, 247-263.

Reynolds, D. 1983. Naikan psychotherapy: Meditation for self-development. Chicago: University of Chicago Press.

Ryan, R. M., \& Frederick, C. 1997. On energy, personality, and health: Subjective vitality as a dynamic reflection of well-being. Journal of Personality, 65, 529-565.

Saito, K., \& Nakamura, M. 1987. Taijin teki shikousei shakudo sakusei no kokoromi [An attempt to construct a scale of interpersonal orientation]. Bulletin of the faculty of Education of Nagoya University, Department of Educational Psychology, 34, 97-109.

Scheier, M. F., Carver, C. S., \& Bridges, M. W. 1994. Distinguishing optimism from neuroticism and trait anxiety, self-mastery, and self-esteem: A reevaluation of the Life Orientation Test. Journal of Personality and Social Psychology, 67, 1063-1078.

Snyder, C. R., Harris, C., Anderson, J. R., Holleran, S. A., Irving, L. M., Sigmon, S. T., et al. 1991. The will and the ways: Development and validation of an individual-differences measure of hope. Journal of Personality and Social Psychology, 60, 570-585.

Swap, W. C., \& Rubin, J. Z. 1983. Measurement of interpersonal orientation. Journal of Personality and Social Psychology, 44, 208-219. 
Taylor, S. E., Sherman, D. K., Kim, H. S., Jarcho, J., Takagi, K., \& Dunagan, M. S. 2004. Culture and social support: Who seeks it and why? Journal of Personality and Social Psychology, 87, 354-362.

Tesser, A., Gatewood, R., \& Driver, M. 1968. Some determinants of gratitude. Journal of Personality and Social Psychology, 9, 233-236.

Tsang, J. 2006a. The effects of helper intention on gratitude and indebtedness. Motivation and Emotion, 30, $198-204$.

Tsang, J. 2006b. Gratitude and prosocial behavior: An experimental test of gratitude. Cognition \& Emotion, 20, 138-148.

Watkins, P. C., Seheer, J., Ovnicek, M., \& Kolts, R. 2006. The debt of gratitude: Dissociating gratitude and indebtedness. Cognition \& Emotion, 20, 217-241.

(Manuscript received April 24, 2008; Revision accepted April 13, 2010) 